\title{
A Method for Optimizing Lightweight-Gypsum Design Based on Sequential Measurements of Physical Parameters
}

\author{
Alena Vimmrová ${ }^{1}$, Václav Kočí2 ${ }^{2}$, Jitka Krejsová ${ }^{2}$ Robert Černý ${ }^{2}$ \\ ${ }^{1}$ Department of Materials Engineering and Chemistry, Faculty of Civil Engineering, Czech Technical University in Prague, \\ Thákurova, 7/2077, 166 29, Prague 6, Czech Republic, vimmrova@fsv.cvut.cz \\ ${ }^{2}$ Department of Materials Engineering and Chemistry, Faculty of Civil Engineering, Czech Technical University in Prague, \\ Thákurova, 7/2077, 166 29, Prague 6, Czech Republic
}

A method for lightweight-gypsum material design using waste stone dust as the foaming agent is described. The main objective is to reach several physical properties which are inversely related in a certain way. Therefore, a linear optimization method is applied to handle this task systematically. The optimization process is based on sequential measurement of physical properties. The results are subsequently point-awarded according to a complex point criterion and new composition is proposed. After 17 trials the final mixture is obtained, having the bulk density equal to (586 \pm 19$) \mathrm{kg} / \mathrm{m}^{3}$ and compressive strength $(1.10 \pm 0.07) \mathrm{MPa}$. According to a detailed comparative analysis with reference gypsum, the newly developed material can be used as excellent thermally insulating interior plaster with the thermal conductivity of $(0.082 \pm 0.005) \mathrm{W} /(\mathrm{m} \cdot \mathrm{K})$. In addition, its practical application can bring substantial economic and environmental benefits as the material contains $25 \%$ of waste stone dust.

Keywords: Lightweight gypsum, waste stone dust, physical properties, optimization, sequential measurement.

\section{INTRODUCTION}

Designing an optimal composition of any composite material is always an experimentally and numerically difficult task. The components of composite materials react synergically and the improvement of one property leads very often to deterioration of other properties [1]-[2]. Speaking of the gypsum based materials, it is practically impossible to find optimal composition based on theoretical experience only and all the designed materials have to be investigated experimentally as well.

Most of the gypsum based materials can be considered as multi-componential. It means, besides gypsum and water, they are also formed by some additives such as plasticizers, setting regulators, fibers, or foaming agents. The approaches aiming at design of multi-componential gypsum based materials have not been very systematic so far. The composition has often been formulated randomly; sometimes it has been based on the results of previous experiments, results obtained from the testing of different binders and recommendations of the producers of the particular additives. These approaches do not take the synergical effects between particular components into account, therefore the optimal composition may be hard to find. Summarizing all the mentioned negatives of current design practice, application of optimization methods for design of gypsum based composites will bring indisputable benefits.

According to the latest literature review only marginal attention has been paid to the application of optimization methods for design of gypsum based composites [3]-[5]. Using the stepwise optimization method, Arikan and Sobolev [3] tried to design the gypsum based plaster. The main principle of this method is to find the optimal amount of the first component. Then, optimal amount of the second component is sought while the amount of the first component remains constant. This method may lead to the design of a material with better properties, however, it may not be the optimal solution as the mutual interaction between the particular components is not considered.

Böse et al. [4] employed factorial experiments in order to design gypsum plaster composite. Design of the factorial experiment consists of two or more factors representing the components, each with several levels (e.g., dosing). The experimental plan is then formulated, consisting of all possible combinations of the levels across all factors. Such an experiment allows studying the effects of each factor on the response variable as well as the effects of interactions between factors on the response variable. It means the interaction between the components is taken into account. On the other hand, the main disadvantage of this method is that in the case of more components the experimental plan is 
very large which makes this method very expensive. If the number of combinations in a full factorial design is too high, a fractional factorial design may be done, in which some of the possible combinations are omitted. In this case there is danger that the optimal (but less probable) composition is not found.

Gencel et al. [5] used the DOE (design of experiment) method to optimize composition of gypsum composites containing vermiculite and polypropylene fibers. DOE is nowadays mostly used for the complex analysis of data and includes the planning and conducting of experiments, evaluation and optimization of results.

In this paper, a linear optimization method was used for the design of a lightweight-gypsum material. This method is commonly used in chemistry [6]-[7], electrical engineering [8]-[9], industrial processes [10], statistics [11], mathematics [12], or other disciplines [13]-[15] where the results can be obtained almost immediately. However, design of composite building materials, cement- and lime-based in particular, is characterized by the technological lags necessary for the development of their structure and properties, which makes this method very time demanding. On the other hand, gypsum as the main binder can relatively quickly create the final structures with fully developed physical properties [16]-[17]. That is the reason why a linear optimization method was used in this paper for identification of optimal composition of lightweight-gypsum composite based on sequential measurement of physical parameters.

\section{MATERIALS \& METHODS}

\section{A. Applied materials}

The chemically foamed gypsum was investigated. It was prepared using four components, namely gypsum, water, acid foaming agent and waste stone dust.

The commercially available gray gypsum produced by Gypstrend, Czech Republic was used as the basic material. The foaming was carried out using carbon dioxide originating from the chemical reaction between aluminum sulfate and calcium carbonate as follows [18]:

$$
\begin{aligned}
& \mathrm{Al}_{2}\left(\mathrm{SO}_{4}\right)_{3}+3 \mathrm{CaCO}_{3}+6 \mathrm{H}_{2} \mathrm{O} \rightarrow 2 \mathrm{Al}(\mathrm{OH})_{3}+ \\
& +3 \mathrm{CaSO}_{4}+3 \mathrm{H}_{2} \mathrm{O}+3 \mathrm{CO}_{2}
\end{aligned}
$$

This kind of foaming was used for the first time nearly 100 years ago [19]. The real novelty brought by this paper lies in the application of waste stone dust as a source of calcium carbonate. The use of waste stone dust provides several economic and ecological benefits. In countries with large stone processing industry the amount of waste dust, emerging from cutting and polishing of stones, has become a serious problem. The dust has been landfilled so far, therefore new possibilities for its utilization have been investigated. The stone dust usually contains a certain amount of calcium carbonate, because of presence of minerals with high calcium carbonate content such as marble, limestone, chalk or travertine. Such dust is then ideal as a foaming trigger.
The applied stone dust, used for the lightweight-gypsum preparation, was taken from a local stonemason producer, Kamenictví Jež, in Beroun, Czech Republic. It was taken in the form of sludge remaining after underwater cutting and was mostly formed by marble and granite. The sludge was dried and then ground to the maximal particle size $100 \mu \mathrm{m}$ (see Fig.1.). The amount of the calcium carbonate in the dust was $68 \%$, which was sufficient enough for successful foaming initiation.

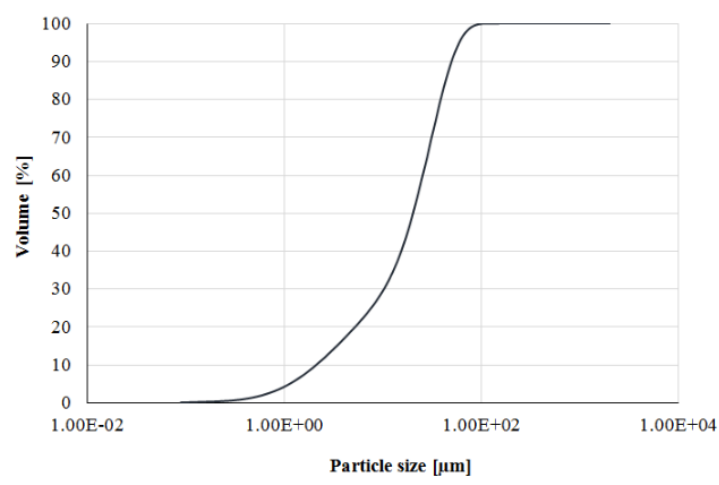

Fig.1. Particle size distribution of stone dust.

Aluminum sulfate entering the chemical reaction described in (1) was a part of the liquid acid agent prepared using 300 $\mathrm{g}$ of aluminum sulfate and $150 \mathrm{~g}$ of citric acid dissolved in 1 liter of water [20]. Both aluminum sulfate and citric acid were standard, commercially available products. Because the aluminum sulfate is usually supplied in the form of very coarse crystals, its dissolution in water is more effective and economical than its grinding to very fine particles, considering its high solubility in particular. The addition of citric acid was necessary because it stabilizes the aluminum sulfate solution against hydrolysis. Moreover, citric acid serves as a retarder of setting as well.

\section{B. Sample preparation and experimental methods}

All lightweight-gypsum materials were prepared using the same procedure. The dry gypsum and stone dust were thoroughly mixed together at first. The measured amount of the liquid acid agent was then filled up with water to get the required volume and the dry mixture of gypsum and dust was added. The blend was mixed in a standard mixer for $30 \mathrm{~s}$ at the speed of $14 \mathrm{rev} / \mathrm{min}$, wiped off and mixed again for another $30 \mathrm{~s}$ at the same speed (see Fig.2.). After the mixing was finished, three standard test prisms $(160 \times 40 \times 40 \mathrm{~mm})$ were prepared. The samples were not compacted and the amount of material exceeding the molds was cut off using a knife several times. After hardening, the specimens were removed from the molds and dried at the temperature of $50{ }^{\circ} \mathrm{C}$ to constant mass.

Besides lightweight samples, also one set of solid nonfoamed gypsum prisms was prepared which was supposed to serve as a reference sample for the quantification of the effectiveness of lightening. The preparation was similar to foamed materials, but no foaming components were added. It means, only gypsum powder with water was used. 
After seven days, the mass of the dry samples was determined and all their dimensions were measured using a digital caliper. The volume of each sample was calculated from the dimensions and the bulk density was determined as a ratio of the mass and volume.

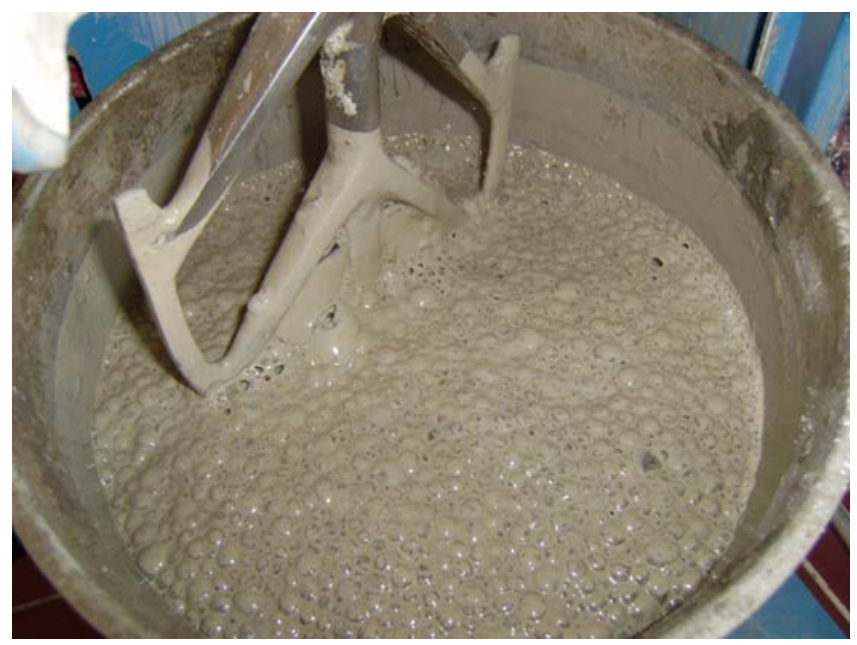

Fig. 2. Preparation of the foamed material in the laboratory mixer.

The compressive strength was determined in accordance with the standard ČSN EN 13279-2 [16] on the standard test prisms.

For the sake of comparison, selected samples were also subjected to the tests of pore size distribution, thermal conductivity and water vapor diffusion ability. The pore size distribution was determined using Mercury Intrusion Porosimetry (MIP, apparatus Pascal $140+440$, Thermo Electron, Italy), thermal conductivity was measured by the pulse method (Isomet 2104, Applied Precision, Ltd., Slovakia) and water vapor diffusion resistance factor was measured using the cup method. A detailed description of these methods can be found in Černý et al. [21].

The measurements of all physical quantities involved certain uncertainties which were generated, e.g., by the statistical processing of data sets, presence of inhomogeneities, or the accuracy of measurement devices. Additionally, these uncertainties may be further enhanced in subsequent calculations. Therefore, a thorough uncertainty analysis of measured data was performed according to ISO/IEC 98-3 [22], which is commonly used in various experimental measurements of physical parameters e.g., [23]-[24]. All the obtained results were provided with expanded standard uncertainty at the confidence level equal to $95 \%$.

\section{Description of the optimization procedure}

The main principle of the applied linear optimization method was to find the optimum of a function with $N$ variables. Having assigned one dimension, all the variables created an $\mathrm{N}$-dimensional space together. Within this space, the simplex with $N+1$ vertices was projected. For instance, two-variable-simplex could be interpreted as triangle and three-variable-simplex as tetrahedron. The simplex with more variables could not be geometrically interpreted, of course [25]. Since the mathematical background of the optimization algorithm is rather extensive and is out of the scope of this journal, it was not included in this paper. However, the detailed information can be found in [26], for example.

In the described optimization each vertex represented a particular mixture, which properties were supposed to be measured experimentally while the coordinates of each vertex represented the mixture composition (the weights of acid agent, stone dust and water related to the weight of gypsum).

The bulk density lower than $600 \mathrm{~kg} / \mathrm{m}^{3}$ and the compressive strength higher than $2 \mathrm{MPa}$ were set as the intended physical properties of the designed material. The stone dust was supposed to be used in the highest possible amount.

Because the bulk density and compressive strength are inversely related and also the influence of the stone dust on the final properties could not be predicted, application of optimization method was necessary. Since the optimization of only one criterion (either bulk density or compressive strength) would inevitably lead to the worsening of the other property, the complex point criterion had to be formulated. The point value was assigned to specific range of measured parameters on the basis of previous measurements, experience, and requirements (see Table 1.). Each vertex (mixture) was then evaluated as a sum of particular point values based on the results of experimental measurements.

The main target was to find the composition of lightweight-gypsum mixture with the highest point value. Based on the data presented in Table 1., it meant the mixture with the lowest bulk density, the highest compressive strength, and the highest amount of contained stone dust was being sought.

Table 1. The point values of the complex optimization criterion.

\begin{tabular}{|l|c|c|c|c|c|c|c|}
\hline \multicolumn{2}{|l|}{ Points } & $-\mathbf{3}$ & $\mathbf{- 2}$ & $\mathbf{- 1}$ & $\mathbf{0}$ & $\mathbf{1}$ & $\mathbf{2}$ \\
\hline Bulk density & {$\left[\mathrm{kg} / \mathrm{m}^{3}\right]$} & $>$ & 750 & 700 & 650 & 600 & $\leq$ \\
850 & - & - & - & - & 650 \\
& & 750 & 700 & 650 & 600 \\
\hline $\begin{array}{l}\text { Compressive } \\
\text { strength }\end{array}$ & {$[\mathrm{MPa}]$} & - & $<$ & 0.5 & $\begin{array}{c}- \\
-1.5\end{array}$ & $>$ \\
\hline $\begin{array}{l}\text { Amount of } \\
\text { stone dust }\end{array}$ & {$[\%]^{*}$} & - & $<8$ & $\begin{array}{c}8- \\
10\end{array}$ & $\begin{array}{c}10- \\
12\end{array}$ & $\begin{array}{c}12- \\
15\end{array}$ & $\begin{array}{c}> \\
15\end{array}$ \\
\hline
\end{tabular}

* from the mass of dry gypsum

After each vertex of the simplex was evaluated, the one with the lowest point value was rejected and projected through the average of the remaining vertices. According to the modification introduced by Nelder and Mead [26], the shape of simplex was modified based on successful or unsuccessful projection in order to reach faster convergence towards the sought optimum. Therefore, operations like expansion, contraction, or shrinkage were allowed, as depicted in Fig.3. The illustrative scheme of the convergence process towards the sought optimum is given in Fig.4. 

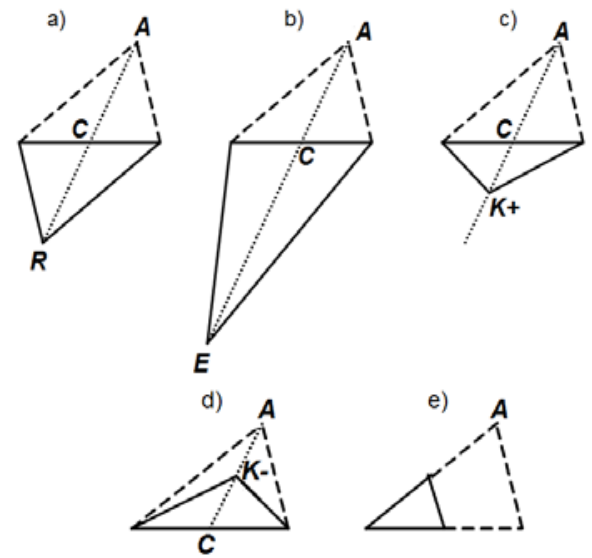

Fig.3. Example of the formation of the new simplex in twodimensional space: a) reflection, b) expansion, c) contraction, d) reflected contraction. e) shrinkage.

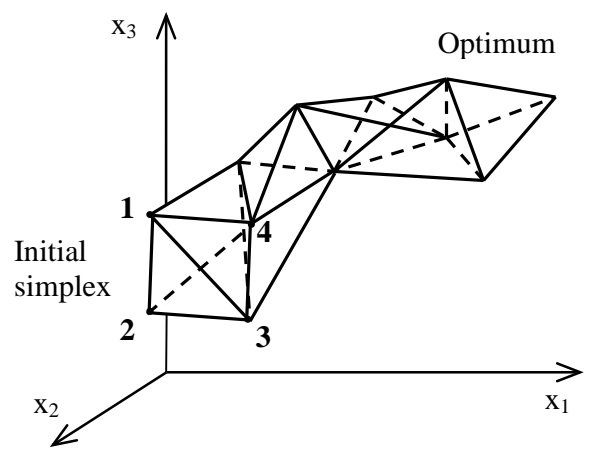

Fig.4. Example of an optimization convergence process in threedimensional space.

All the optimization-related calculations were conducted using the freeware computer code SOVA 1.0 [27] according to the following algorithm:

1. The optimized property is defined (in this case the point evaluation) and the target value is set.

2. For each variable (in this case for each component of the mixture) the initial lower and upper values are defined. They can come out from the previous experience or from the producer's recommendation.

3. Based on the defined upper and lower values, the vertices of the initial simplex are proposed.

4. The mixtures corresponding to the vertices of the initial simplex are prepared, experimentally investigated and point-awarded. Based on these results, the vertex with the lowest point value is rejected and the new vertex is proposed.

5. The new mixture is prepared, experimentally investigated, point-awarded and compared to the value of the rejected vertex. One of the operations presented in Fig.3. is then performed and the new simplex is created.

6. The vertex of the newly created simplex with the lowest point value is rejected and the new vertex is proposed.
7. The optimization process ends when the objective is reached or when the responses (i.e., experimental results) cannot be improved anymore.

\section{RESULTS \& DISCUSSION}

Four vertices (labeled as GL1 - GL4) of the initial simplex were formulated based on the previous experience with the dosage of the particular components (see Table 2.). After the mixtures had been prepared, their bulk density and compressive strength were determined and they were pointawarded. The composition of the new mixture GL5 was then proposed and the prepared specimens were tested. Following this procedure repeatedly, 17 mixture compositions were proposed step by step (see Table 3.) and their physical properties were analyzed.

Table 2. Limiting values of the components for the initial simplex.

\begin{tabular}{|c|c|c|c|}
\hline & $\begin{array}{c}\text { Stone } \\
\text { dust }\end{array}$ & $\begin{array}{c}\text { Acid } \\
\text { components }\end{array}$ & $\begin{array}{c}\text { Water/gypsum } \\
\text { ratio }\end{array}$ \\
\cline { 2 - 4 } & {$[\%]$} & {$[\%]$} & {$[-]$} \\
\hline Lower limit & 8 & 12 & 0.7 \\
\hline Upper limit & 10 & 14 & 0.8 \\
\hline
\end{tabular}

Table 3. Composition of the lightweight gypsum mixtures.

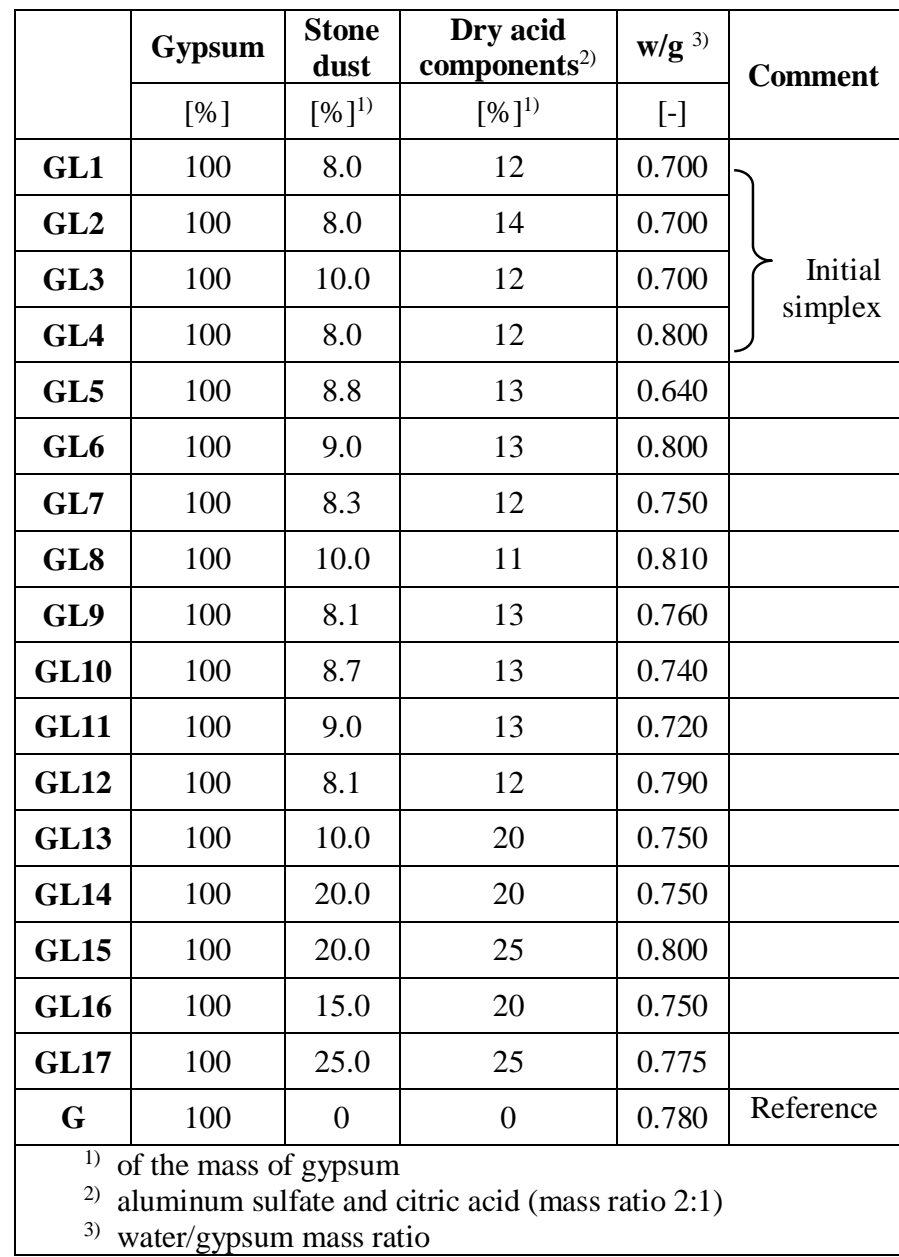


MEASUREMENT SCIENCE REVIEW, 16, (2016), No. 3, 160-166

Table 4. Properties of designed mixtures and values of point criterion.

\begin{tabular}{|c|c|c|c|c|c|c|c|}
\hline & $\begin{array}{c}\text { Stone } \\
\text { dust }\end{array}$ & \multirow{2}{*}{$\begin{array}{l}\text { Point } \\
\text { value }\end{array}$} & Bulk density & \multirow{2}{*}{$\begin{array}{l}\text { Point } \\
\text { value }\end{array}$} & $\begin{array}{l}\text { Compressive } \\
\text { strength }\end{array}$ & \multirow{2}{*}{$\begin{array}{l}\text { Point } \\
\text { value }\end{array}$} & \multirow{2}{*}{$\begin{array}{c}\text { Complex point } \\
\text { criterion }\end{array}$} \\
\hline & $\%$ & & {$\left[\mathrm{~kg} / \mathrm{m}^{3}\right]$} & & [MPa] & & \\
\hline GL1 & 8.0 & -1 & $1010 \pm 13$ & -3 & $3.30 \pm 0.23$ & 2 & -2 \\
\hline GL2 & 8.0 & -1 & $908 \pm 17$ & -3 & $3.10 \pm 0.19$ & 2 & -2 \\
\hline GL3 & 10.0 & 0 & $964 \pm 21$ & -3 & $2.70 \pm 0.31$ & 2 & -1 \\
\hline GL4 & 8.0 & -2 & $747 \pm 45$ & -1 & $0.80 \pm 0.02$ & -1 & -4 \\
\hline GL5 & 8.8 & -2 & $1069 \pm 22$ & -3 & $5.20 \pm 0.39$ & 2 & -3 \\
\hline GL6 & 9.0 & -1 & $791 \pm 19$ & -2 & $1.40 \pm 0.08$ & 0 & -3 \\
\hline GL7 & 8.3 & -1 & $893 \pm 11$ & -3 & $1.46 \pm 0.04$ & 0 & -4 \\
\hline GL8 & 10.0 & 0 & $867 \pm 15$ & -3 & $1.10 \pm 0.03$ & 0 & -3 \\
\hline GL9 & 8.1 & -1 & $832 \pm 18$ & -2 & $1.52 \pm 0.08$ & 1 & -2 \\
\hline GL10 & 8.7 & -1 & $810 \pm 9$ & -2 & $1.63 \pm 0.11$ & 1 & -2 \\
\hline GL11 & 9.0 & -1 & $878 \pm 14$ & -3 & $2.10 \pm 0.23$ & 2 & -2 \\
\hline GL12 & 8.1 & -1 & $794 \pm 18$ & -2 & $1.40 \pm 0.07$ & 0 & -3 \\
\hline GL13 & 10.0 & 0 & $651 \pm 12$ & 1 & $0.60 \pm 0.02$ & -1 & 0 \\
\hline GL14 & 20.0 & 2 & $736 \pm 18$ & -1 & $1.90 \pm 0.22$ & 1 & 2 \\
\hline GL15 & 20.0 & 2 & $803 \pm 9$ & -2 & $2.10 \pm 0.21$ & 2 & 2 \\
\hline GL16 & 15.0 & 2 & $607 \pm 14$ & 1 & $1.30 \pm 0.09$ & 0 & 3 \\
\hline GL17 & 25.0 & 2 & $586 \pm 19$ & 2 & $1.10 \pm 0.07$ & 0 & 4 \\
\hline G* & 0.0 & - & $964 \pm 20$ & - & $5.90 \pm 0.41$ & - & - \\
\hline
\end{tabular}

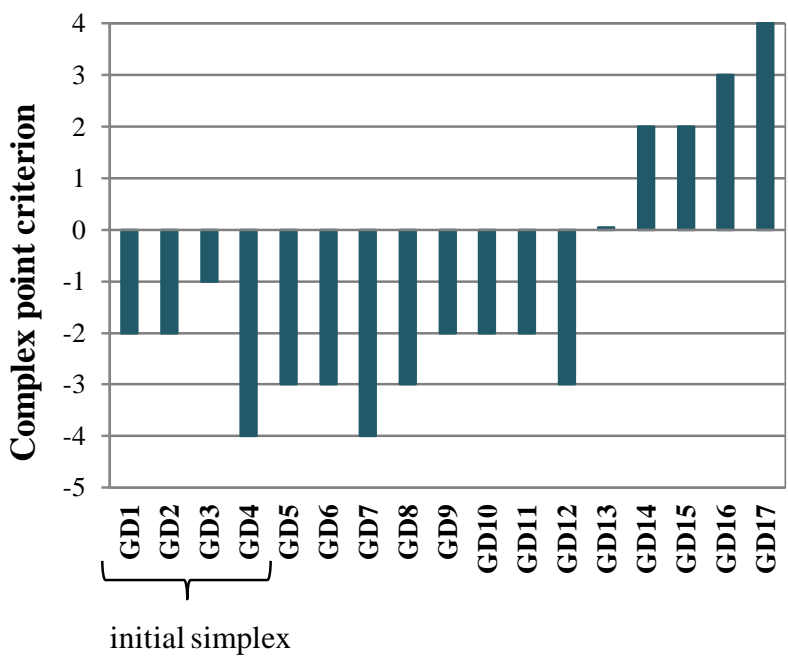

Fig.5. Complex point criterion.

The properties of all mixtures are summarized in Table 4. It can be concluded that the mixture GL16 already reached the acceptable parameters and the mixture GL17 can be considered as the optimized material. The bulk density of the mixture GL17 was $(586 \pm 19) \mathrm{kg} / \mathrm{m}^{3}$, its compressive strength was $(1.10 \pm 0.07) \mathrm{MPa}$ and the amount of contained stone dust was $25 \%$. Speaking about bulk density, the final reached value was even lower than the set target. At the same time, the mixture GL17 contained the highest amount of stone dust of all designed mixtures. Although the value of compressive strength of GL17 did not reach the intended $2 \mathrm{MPa}$, it could still be considered as sufficient.
The convergence of the optimization process towards the sought optimum is illustrated in Fig.5., where the point complex criterion of particular mixtures is shown.

After the optimization process, the pore size distribution, thermal conductivity, and water vapor diffusion resistance factor were measured for solid (non-foamed) gypsum $\mathrm{G}$ as a reference material, GL14 as a material with the middle bulk density, and GL17 as the result of optimization. The summary of measurements is given in Table 5., the pore size distribution is captured in Fig.6.

The porosity of the most lightweight material GL17 was more than $26 \%$ higher than the porosity of non-foamed gypsum $\mathrm{G}$. It was also obvious that the $\mathrm{CO}_{2}$-induced pores were mostly larger than $100 \mu \mathrm{m}$, whereas in the non-foamed gypsum these pores practically did not exist. The difference in the pore structure could be observed with the naked eye (Fig.7.).

Table 5. Properties of selected mixtures.

\begin{tabular}{|c|c|c|c|}
\hline & Porosity & $\begin{array}{c}\text { Coefficient of } \\
\text { thermal } \\
\text { conductivity }\end{array}$ & $\begin{array}{c}\text { Water vapor } \\
\text { diffusion } \\
\text { resistance factor } \\
\text { (dry cup/wet cup) }\end{array}$ \\
\cline { 2 - 4 } & {$[\%]$} & {$[\mathrm{W} /(\mathrm{m} \mathrm{K})]$} & {$[-]$} \\
\hline G & 61.5 & $0.203 \pm 0.011$ & $5.23 / 3.81$ \\
\hline GL14 & 71.6 & $0.090 \pm 0.006$ & $4.59 / 2.93$ \\
\hline GL17 & 77.6 & $0.082 \pm 0.005$ & $3.83 / 2.46$ \\
\hline
\end{tabular}




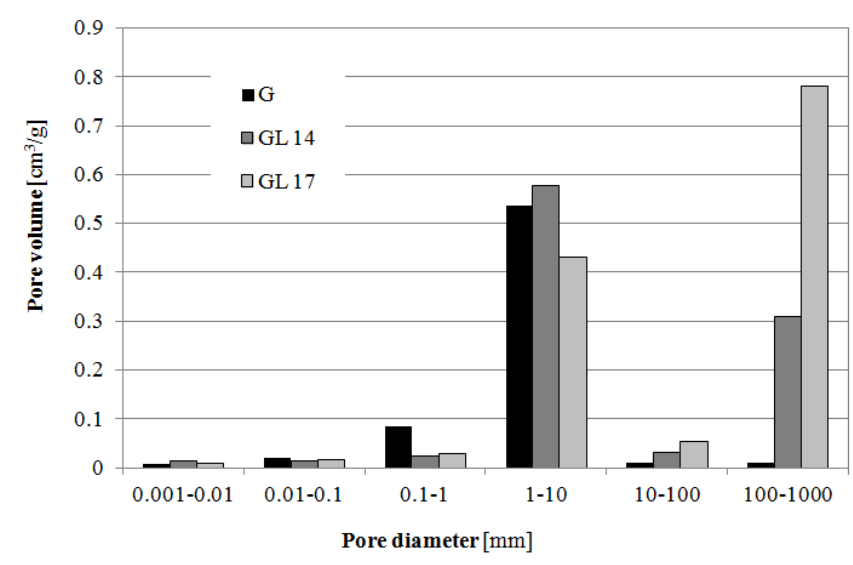

Fig.6. Pore size distribution of selected mixtures.

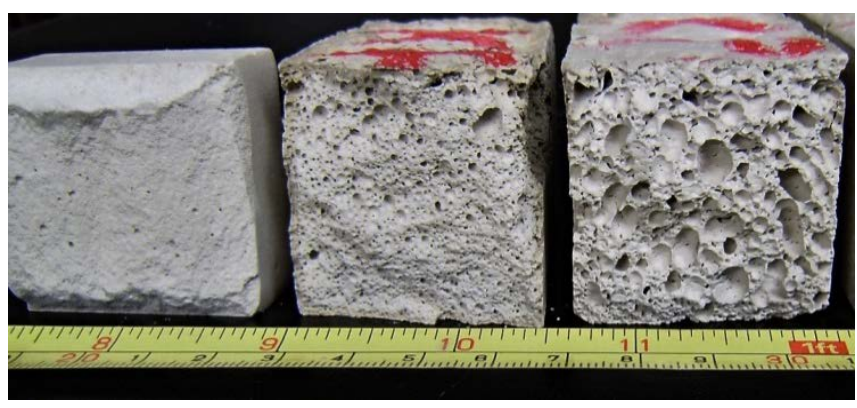

Fig.7. Structure of the materials with different bulk density. From left: reference material G (bulk density $964 \pm 20 \mathrm{~kg} / \mathrm{m}^{3}$ ), GL14 $\left(736 \pm 18 \mathrm{~kg} / \mathrm{m}^{3}\right), \operatorname{GL} 17\left(586 \pm 19 \mathrm{~kg} / \mathrm{m}^{3}\right)$.

As it has been expected, the thermal conductivity of lightweight materials was significantly lower than that of solid gypsum. Since their values were lower than $0.1 \mathrm{~W} /(\mathrm{m} \cdot \mathrm{K})$, they could be classified as thermally insulating materials.

Having an open and breathable structure, already solid gypsum materials are considered as water vapor permeable. The permeability of the lightweight-gypsum materials was even higher; the water vapor resistance factor of GL17 was about $30 \%$ lower than that of the solid gypsum G.

Apparently, the properties of GL17 predispose it to be used as an excellent permeable and thermally insulating interior plaster. Even if high water vapor permeability of interior plasters might be sometimes problematic from the hygric point of view, there are some cases when it might be convenient and desirable. Renovation of wet masonry can be mentioned in that respect, because plasters with high water vapor permeability enable humidity contained in building structures to be quickly released into the environment. GL17 can be also used for production of lightweight precast blocks or as thermal insulating plasterboards.

\section{CONCLUSIONS}

A lightweight-gypsum material with suitable physical properties was designed using a linear optimization method. The reason for its application was the obvious difficulties with the traditional design methods in this case; the particular components influenced each other synergically or inversely. Moreover, the course and kinetics of foaming reactions depend on many factors, making the properties of final materials hardly predictable. Without any systematic optimization the required results would have been achieved only after a significantly higher number of experiments and perhaps they would not have been achieved at all.

The linear optimization method proved to be a useful tool for the design of materials with desired properties, though it is not suitable for long lasting experiments. In the described case one step lasted 7 days, which was still acceptable. It was necessary to use a complex point criterion as a tool for the assessment of several parameters simultaneously; the optimization of only one property usually leads to the worsening of the others and the evaluation of all the requirements together would be unfeasible.

The results presented in the paper showed that a usable lightweight-gypsum material can be prepared using waste stone dust. The designed material is environmentally friendly and its production is economically effective as well. Its production is simple and does not require any special equipment. The optimized material has a bulk density of $(586 \pm 19) \mathrm{kg} / \mathrm{m}^{3}$ and the compressive strength $(1.10 \pm 0.07) \mathrm{MPa}$. Although the strength did not achieve the initially intended value, it could still be considered as sufficient for non-bearing building components. Such a material can be used as thermal insulating plaster, in the lightweight and thermal insulating plasterboards, or for the production of lightweight precast blocks.

\section{ACKNOWLEDGMENT}

This research was supported by the Czech Science Foundation, under project No. 16-01438S.

\section{REFERENCES}

[1] Firestone, M.A., Hayden, S.C., Huber, D.L. (2015). Greater than the sum: Synergy and emergent properties in nanoparticle-polymer composites. MRS Bulletin, 40 (9), 760-767.

[2] Stefanou, G., Sawas, D., Papadrakakis, M. (2015). Stochastic finite element analysis of composite structures based on material microstructure. Composite Structures, 132, 384-392.

[3] Arikan, M., Sobolev, K. (2002). The optimization of a gypsum-based composite material. Cement and Concrete Research, 32 (11), 1725-1728.

[4] Böse, H., Hurbanic, M., Raether, F. (1996). Optimization of gypsum plaster composition supported by experimental design. ConChem Journal, 1996 (4), 64-71. 
[5] Gencel, O., del Coz Diaz, J.J., Sutcu, M., Koksal, F., Alvarez Rabanal, F.P., Martinez-Barrera, G., Brostow, W. (2014). Properties of gypsum composites containing vermiculite and polypropylene fibers: Numerical and experimental results. Energy and Buildings, 70, 135-144.

[6] Jinzhi, W., Guili, L., Xinjun, X., Chunyan, X., Wenjing, D., Jun, X. (2014). Simplex optimization for aloe-emodin separation and purification using aqueous double-phase extraction system. Journal of Liquid Chromatography \& Related Technologies, 37 (5), 653663.

[7] Kanka, J. (2013). Design of turn-around-point longperiod gratings in a photonic crystal fiber for refractometry of gases. Sensors and Actuators BChemical, 182, 16-24.

[8] Feres, M.M., Floridia, C., Romero, M.A. (2015). Optimisation algorithms for OSNR measurement based on polarisation nulling. Eletronics Letters, 51 (13), 1007-1009.

[9] Neto, L.A., Erasme, D., Genay, P., Chanclou, P., Deniel, Q., Traore, F., Anfray, T., Hmadou, C., Aupetit-Berthelemot, C. (2013). Simple estimation of fiber dispersion and laser chirp parameters using the downhill simplex fitting algorithm. Journal of Lightwave Technology, 31, 334-342.

[10] Rios-Mercado, R.Z., Borraz-Sanchez, C. (2015). Optimization problems in natural gas transportation systems: A state-of-the-art review. Applied Energy, 147, 536-555.

[11] Benati, S. (2011). Heuristic methods for the optimal statistic median problem. Computers \& Operations Research, 38 (1), 379-386.

[12] Scotti, T., Wirgin, A. (2014). Multiparameter identification of a lossy fluid-like object from its transient acoustic response. Inverse Problems in Science and Engineering, 22, 1228-1258.

[13] Bayer, T. (2014). Estimation of an unknown cartographic projection and its parameters from the map. Geoinformatica, 18, 621-669.

[14] Martínez, J.L., Reina, A.J., Mandow, A., Morales, J. (2012). 3D registration of laser range scenes by coincidence of coarse binary cubes. Machine Vision and Application, 23, 857-867.
[15] Mariani, V.C., Coelho, L.D. (2011). A hybrid shuffled complex evolution approach with pattern search for unconstrained optimization. Mathematics and Computers in Simulation, 81, 1901-1909.

[16] Czech Office for Standards, Metrology and Testing. (2014). Gypsum binders and gypsum plasters. Test methods. CSN EN 13279-2.

[17] Czech Office for Standards, Metrology and Testing. (1979). Gypsum binding materials. ČSN 722301.

[18] Colak, A. (2000). Density and strength characteristics of foamed gypsum. Cement \& Concrete Composites, 22 (3), 193-200.

[19] Gamara, Ch. (1933). Method of making aerated gypsum and resulting product. US Patent 1912702.

[20] Svoboda, L., Vimmrová, A. (2007). Acid agent for preparation of foamed gypsum. Czech utility design no. 17844, Prague.

[21] Černý, R. (2013). Complex System of Methods for Directed Design and Assessment of Functional Properties of Building Materials and Its Applications. Prague, Czech Republic: Czech Technical University.

[22] International Organization for Standardization. (2008). Evaluation of measurement data - Guide to the expression of uncertainty in measurements. ISO/EIC Standard 98-3:2008.

[23] Štubňa, I., Šín, P., Trník, A., Vozár, L. (2014). Measuring the flexural strength of ceramics at elevated temperatures - an uncertainty analysis. Measurement Science Review, 14 (1), 35-40.

[24] Vrba, I., Palencar, R., Hadzistevic, M., Strbac, B., Spasic-Jokic, V., Hodolic, J. (2015). Different approaches in uncertainty evaluation for measurement of complex surfaces using coordinate measuring machine. Measurement Science Review, 15 (3), 111118.

[25] Watters, F.H., Parker, L.R., Morgan, S.L., Deming, S.N. (1991). Sequential Simplex Optimization. CRC Press.

[26] Nelder, J.A., Mead, R. (1965). A simplex method for function minimization. Computer Journal, 7, 308-313.

[27] Svoboda, L. (2012). SOVA 1.0 [software]. http://people.fsv.cvut.cz/ svobodal/sova/

Received March 07, 2016. Accepted May 27, 2016. 